\title{
Software Based Approach for Teaching in Electrical Engineering Classroom Courses: a Case Study
}

\author{
Hemant Mehar \\ Department of Electrical \& Electronics Engineering, Institute of Engineering \& Science, \\ IPS Academy, Indore Madhya Pradesh, India \\ E-mail: meharhemant@yahoo.com
}

\begin{abstract}
As the day by day changes in the technology, technical requirements and techniques of the industry changes simultaneously. Therefore the requirements to educate our students not only the conceptual as well as new approaches based on the latest techniques. Involvement of software in teaching is not only providing a better support, more clear and visual operation of complex circuits and waveforms of the faculty of power electronics in classroom teaching as well as to the student to understand a better concept. The software packages available for simulation of power electronic circuits are MATLAB, PSPICE and PSIM and many more. In this paper author takes an example of an AC voltage controller to explain the software based teaching approach. Author used two software based simulation tool to explain the AC Voltage Controller and compare the software based approach with the blackboard \& PPT Presentation based technique. This paper is helpful for the faculty of electrical engineering to find the applications of MATLAB/SIMULINK and PSIM in teaching.
\end{abstract}

Keywords: teaching, education, AC-AC converter, software, engineering

Copyright $(2015$ Institute of Advanced Engineering and Science. All rights reserved.

\section{Introduction}

The software has grown in popularity, its usage in the educational field has become an important preoccupation for more and more universities all over the world. In electrical engineering, software environments like MATLAB and PSIM have now the potential to enhance the content of a large variety of courses, offering teachers the opportunity to develop new educational. There are various softwares for learning the different subjects of electrical engineering like circuit theory, control system, power system, power electronics and drive [1].

AC Voltage controllers are thyristor based devices which convert fixed alternating voltage directly to variable alternating voltage without a change in the frequency (Figure 1). Some of the main applications of ac voltage controllers are for domestic and industrial heating, transformer tap changing, lighting control, speed control of single phase and three phase ac drives and starting of induction motors. Earlier, the devices used for these applications were auto-transformers, tap-changing transformers, magnetic amplifiers, saturatable reactors etc. but these devices are now replaced by thyristor and triacs based ac voltage controllers because controllers are also adaptable for closed loop control systems. Since the ac voltage controllers are phase controlled devices, thyristors and triacs are line commutated and as such no complex commutation circuitry is required in these controllers.

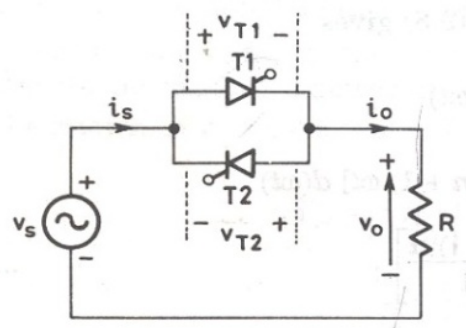

Figure 1. Single - Phase full wave AC voltage controller 


\section{The Case Study}

\subsection{Blackboard Technique in Real Classroom}

The case study is done on the topic of the power electronics subject under the electrical engineering courses world wild universities. For explaining this topic to our students in a classroom, we need to make the circuit on the blackboard, as shown in the capture Figure 2.

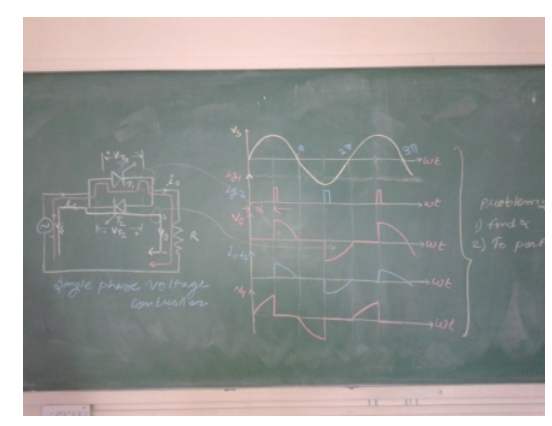

Figure 2. Blackboard captured image from classroom

To explain the software utility, I applied the different way in the classroom and captured some images for different types of $A C$ voltage controller circuits., due to the lake of space I have shown here just few number images from the classroom, those are sufficient to explain the applied methodology. Here I need to make the circuit on blackboard and with these needs to make the waves for this particular circuit by taking some imaginary angle $\alpha$. In this blackboard I take it at 90 degrees. I need a lot of time to make this circuit and respective waves and even I want to change the firing angle, I unable to do in the same and if, I come a very bad presentation. Here whole the process is just an imaginary, operation of the devices and drawing their waves is also a typical and time consuming tasks.

\subsection{Presentation Technique in Real Classroom}

For the better understanding and for the time saving and for clear views, we can also adapt a presentation techniques, this method of teaching is also shown in the below captured Figure 6 \& Figure 7 . These methods are providing lots of simplicity to explain concepts of working of $A C$ voltage controller, but with this we need also the imagination of operation of circuits.

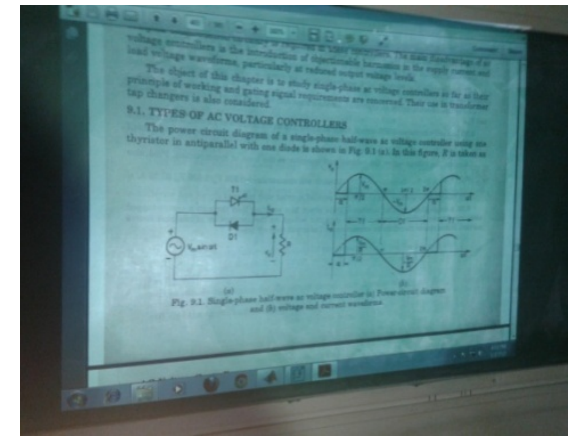

Figure 3. Blackboard captured image from classroom of Presentation

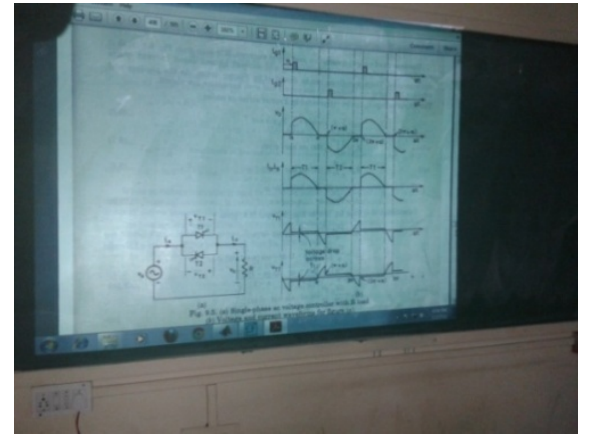

Figure 4. Blackboard captured image from classroom of Presentation

\subsection{Simulation Technique in Real Classroom}

Below captured Figures 5-8 shown the applicability of the proposed method. Here the authors use the two simulation tools for explaining the $A C$ voltage controller, i.e. 
MATLAB/SIMULINK and PSIM. Here we can easily explain the operation of these circuits by drawing just in a few seconds or by pre preparing for this circuit and just simulate and run it in front of the student in the classroom. These provide a virtual operation and with the help of the input pulses we can easily change the shape/performance of the circuit and devices.

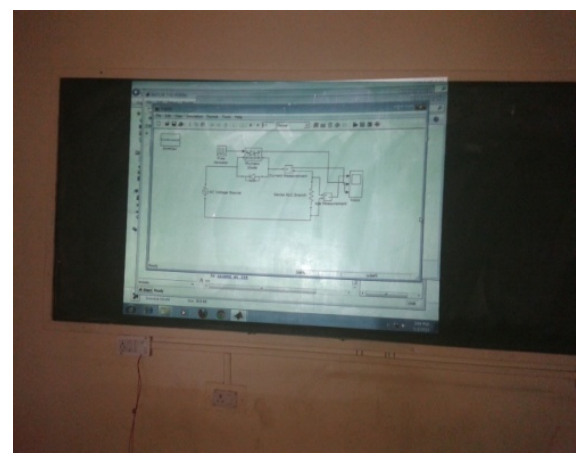

Figure 5. captured image from classroom of teaching using MATLAB/SIMULINK Software

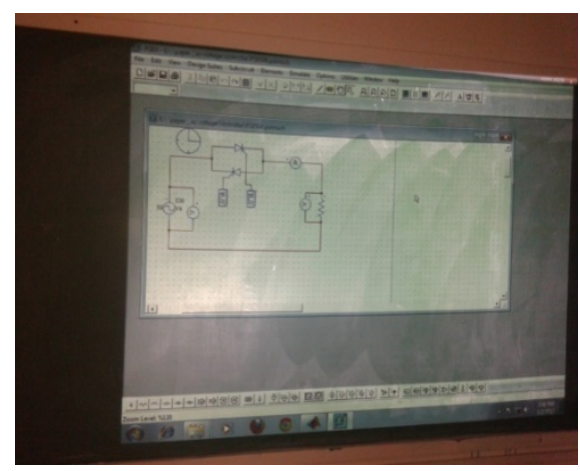

Figure 7. Captured image from classroom of teaching using PSIM Software

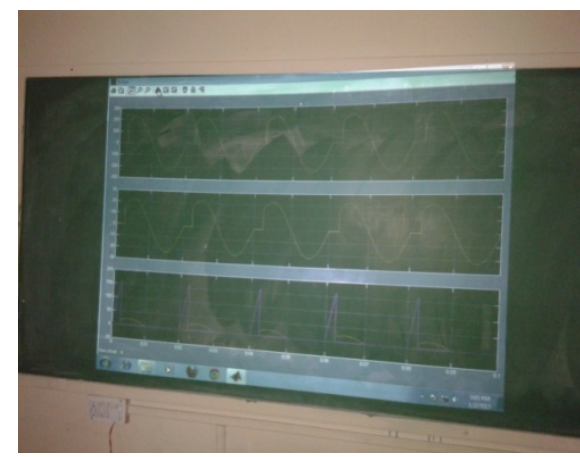

Figure 6. Captured image from classroom of teaching using MATLAB/SIMULINK Software

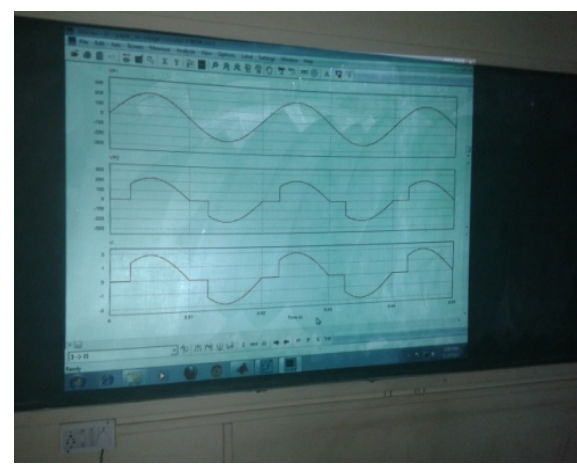

Figure 8. Captured image from classroom of teaching using PSIM Software

\section{Results and Analysis}

\subsection{MATLAB/SIMULINK Based Simulation}

MATLAB/SIMULINK based Simulation model for AC voltage controller is shown in fig. below. The performance of the devices is represented with the help of waveforms in figure. In this figure the waves for output voltage, current and $V$ \& I across the device are shown, for the simplicity of the concept of learning and presentation of proposed method here only a resistive load is considered.

Here with the change of the setting of the Pulse Generator we can easily change the firing angle of the device. We can also adopt the different firing schemes, but for this particular application the pulse generator is the best suitable option. For the different type of the load we can choose the different types of filtering circuits to improve the operation. 


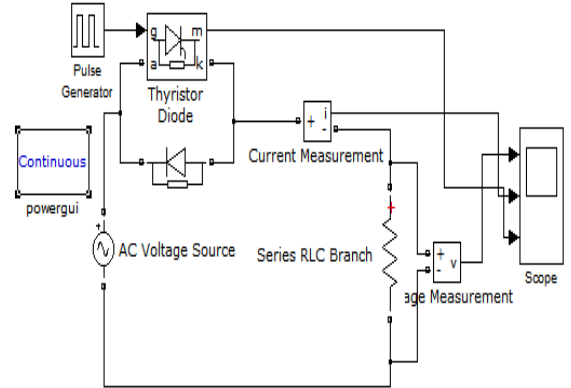

Figure 9. Simulation Model of Single Phase half Wave AC Voltage Controller

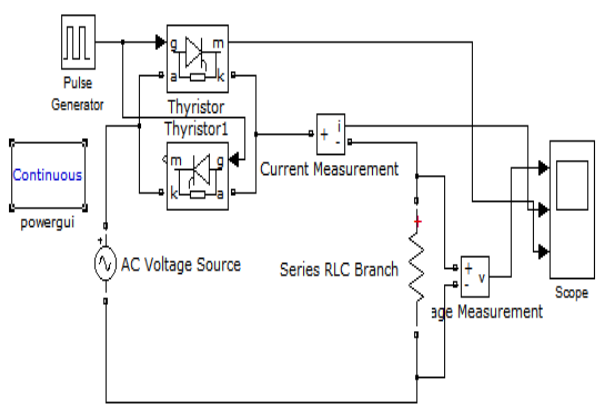

Figure 11. Simulation Model of Single Phase full wave AC Voltage Controller

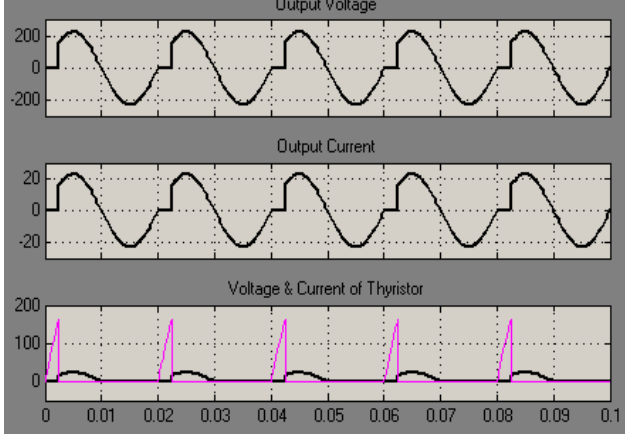

Figure 10. Output Waveforms of Single Phase half wave AC Voltage Controller

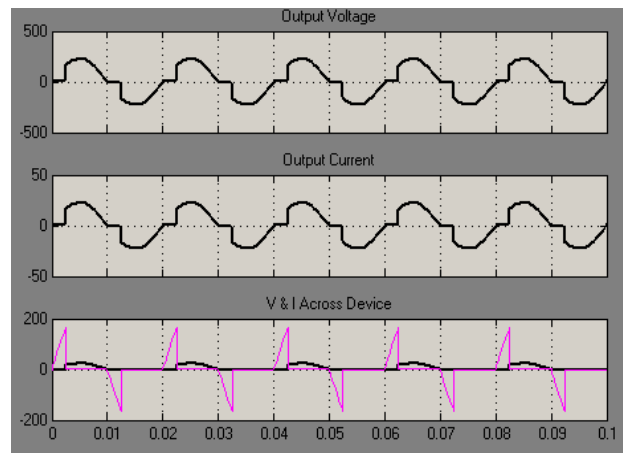

Figure 12. Simulation Model of Single Phase full wave AC Voltage Controller

\subsection{PSIM Based Simulation}

A PSIM based Simulation model for AC voltage controller is shown in figures below. The performance of the devices is represented with the help of waveforms in figures. In this figures the waves for output voltage, current and V \& I across the device are shown. For simplicity of the concept of learning and presentation of proposed method here only a resistive load is considered.

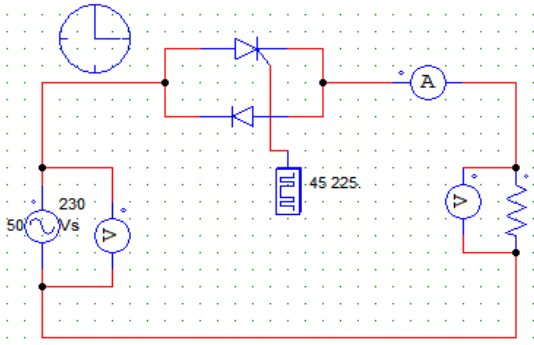

Figure 13. Simulation Model of Single Phase half wave AC Voltage Controller
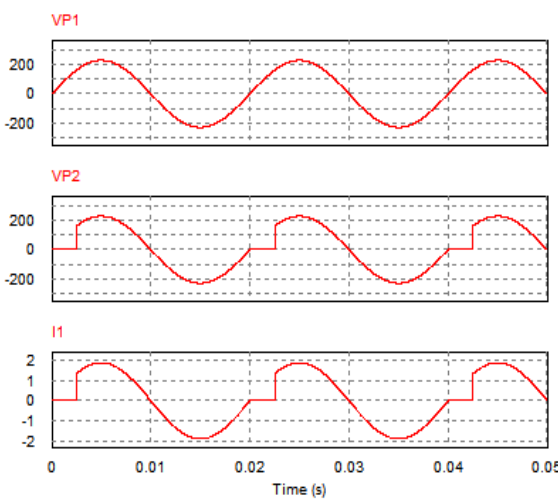

Figure 14. Output of Single Phase half wave AC Voltage Controller 


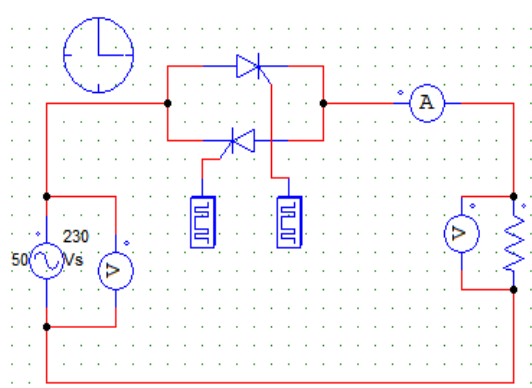

Figure 15. Simulation Model of Single Phase full wave AC Voltage Controller
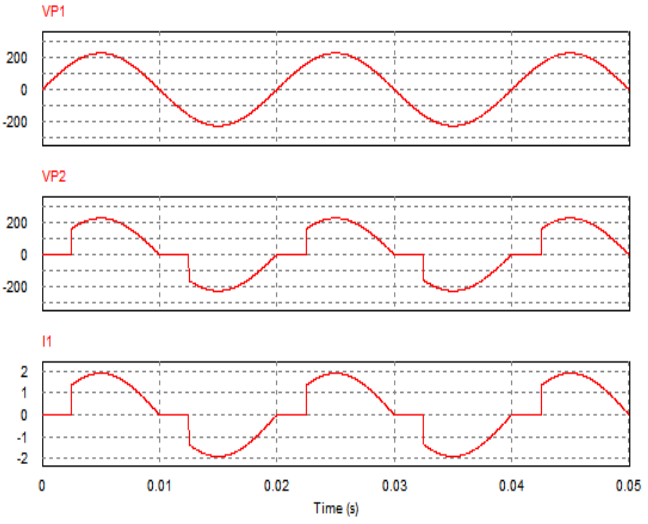

Figure 16. Output of Single Phase half Wave AC Voltage Controller

Here with the change of the setting of the Gate Pulse we can easily change the firing angle of the device. We can also adopt the different firing schemes, but for this particular application the pulse generator is the best suitable option. For the different type of the load we can choose the different types of filtering circuits to improve the operation.

Table 1. Comparison between Blackboard, Presentation and Software Approach

\begin{tabular}{|c|c|c|c|}
\hline Parameters & Blackboard & Presentation & Software \\
\hline Circuit making time & Around 2 minutes & Less than 1 minutes & Less than 1 minutes \\
\hline $\begin{array}{l}\text { Output waves drawing } \\
\text { time }\end{array}$ & Approx. 5-10 minutes & Shown by fig. & $\begin{array}{l}\text { In few seconds based on } \\
\text { simulation time }\end{array}$ \\
\hline Clarity of performance & $\begin{array}{l}\text { Depends upon } \\
\text { drawing }\end{array}$ & Much higher & Much higher \\
\hline Pre-preparation & Must/use notes & Required & $\begin{array}{l}\text { Performance shown by } \\
\text { simulation }\end{array}$ \\
\hline Modification & Not possible & Not possible & Easily possible \\
\hline Firing angles & $\begin{array}{l}\text { Fixed and unable to } \\
\text { change }\end{array}$ & $\begin{array}{l}\text { Easily changed by simple } \\
\text { resetting }\end{array}$ & $\begin{array}{l}\text { Easily changed by simple } \\
\text { resetting }\end{array}$ \\
\hline Explanation level & Poor & Higher & Higher \\
\hline Circuit making time & Around 2 minutes & Less than 1 minutes & Less than 1 minutes \\
\hline $\begin{array}{l}\text { Output waves drawing } \\
\text { time }\end{array}$ & Approx. 5-10 minutes & Shown by fig. & $\begin{array}{l}\text { In few seconds based on } \\
\text { simulation time }\end{array}$ \\
\hline Clarity of performance & $\begin{array}{l}\text { Depends upon } \\
\text { drawing }\end{array}$ & Much higher & Much higher \\
\hline Pre-preparation & Must/use notes & Required & $\begin{array}{l}\text { Performance shown by } \\
\text { simulation }\end{array}$ \\
\hline Modification & Not possible & Not possible & Easily possible \\
\hline Firing angles & $\begin{array}{l}\text { Fixed and unable to } \\
\text { change }\end{array}$ & $\begin{array}{l}\text { Easily changed by simple } \\
\text { resetting }\end{array}$ & $\begin{array}{l}\text { Easily changed by simple } \\
\text { resetting }\end{array}$ \\
\hline Explanation level & Poor & Higher & Higher \\
\hline Circuit making time & Around 2 minutes & Less than 1 minutes & Less than 1 minutes \\
\hline
\end{tabular}

\section{Advantages and Limitations of Software Approach}

The following advantages derived when using Software in teaching power electronics courses:

1) It provides better visual operation of power electronics converters.

2) Use of software in classroom save the time of the faculty.

3) With user-friendly interface, simulation speed, capability of simulating any type of power converters and control circuits.

4) Students can use this software for their project works. 
This paper provides a basic approach to deal with the software. The only limitation with this software approach is that the knowledge of computer and depth knowledge of power electronics subject is necessary to identify the truth results.

\section{Conclusion}

This case study provides the visual operations of power electronics converters. This Paper provides a comparison between blackboard \& presentation approach verses software approach. As power electronic systems are getting more complex today, the simulation used for education is requiring more features. This approach is time saving and some directions in the development of simulation are discussed in this paper, with the help of present model students can simulate the power electronics circuit with various load \& conditions.

\section{Acknowledgements}

The author would like to thank to working organization, IES IPS Academy, and the department of Electrical \& Electronics Engineering for providing the resources for this work. The author also would like to thank the students, faculties and readers of my papers for their valuable suggestions.

\section{References}

[1] Hemant Mehar. Software Application In Under Graduate Electrical Engineering Education. International Journal of Engineering Research \& Technology (IJERT). 2012; 1(10): 2012.

[2] https://www.mathworks.com/accesslogin/login.do?uri=http\%3A\%2F\%2Fwww.mathworks.in\%2Fdownl oads $\% 2$ student_downloads $\% 2$ Findex.

[3] http://www.powersimtech.com/index.php?name=download.

[4] Bhimbra PS. Power Electronics. 4th Ed. Khanna Publication. 2007.

[5] Muhammad H Rashid. Power electronics, circuit devices and application. 3rd Ed. Pearson education Inc. 2007.

[6] PC Sen. Power electronics. Tata McGraw-Hill publishing company. 2008.

[7] BK khanchandani. Power electronics. Tata McGraw-Hill publishing company. 2008.

[8] Prof Sabyasachi Sengupta, et al. NPTEL Power Electronics Notes. Available: nptel.iitm.ac.in.

[9] Hemant Mehar. MATLAB Simulation Techniques in Power Electronics. IEEE Technology and Engineering Education (ITEE). 2012; 7(4): 62.

[10] Chung Kuo, Jack Hsieh, Firuz Zare, Gerard Ledwich. An Interactive Educational Learning Tool for Power Electronics. Conf. Power Engineering, Australasian Universities, AUPEC. 2007.

[11] PJ van Duijsen, P Bauer, B Davat. Simulation and Animation of Power Electronics and Drives, Requirements for Education. Available: www.simulation-research.com.

[12] Rajesh Verma, Ashu Gupta, Kawaljeet Singh. Simulation Software Evaluation and Selection: A Comprehensive Framework. J. Automation \& Systems Engineering. 2008: 221-234.

[13] I.G. Pacheco, J.G. Matias, "A Methodology Based on Effective Practices to Develop Educational Software", in Computacion y Sistemas, Vol. 11, No. 4, pp. 313-332, 2008.

[14] Palit SK, Mani N, Lithgow B. Computer aided undergraduate electronic study programme. Proc. Pacific Region Conf. on Electrical Engng. Educ. (PRCEEE,97). Wollongong University, NSW, Australia. 1997: 163-168.

[15] Sameer Khader. The Application of PSIM \& MATLAB/SIMULINK in power electronics courses. Conf. Learning Environments and Ecosystems in Engineering Education, IEEE Global Engineering Education Conference (EDUCON). Amman, Jordan. 2010.

[16] Kapilevich B, Shaibon H, Rahman TA. Simulation modeling in electrical engineering: experience of teaching in University Technology of Malaysia. IEEE First International Conference on Multi-Media Engineering Education Proceedings. 1994: 92-98.

[17] Kevin M Passino. Teaching Professional and Ethical Aspects of Electrical Engineering to a Large Class. IEEE Trans. Educ. 1998; 41(4): 149-154.

[18] Hemant Mehar. The Case Study of Simulation of Power Converter Circuits Using Psim Software in Teaching. American Journal of Educational Research. 2013; 1(4): 137-142.

[19] WW Cooley, P Klinkhachorn, RL McConnell, NT Middleton. Developing professionalism in the electrical engineering classroom. IEEE Trans. Educ. 1991; 34: 149-154.

[20] Euzeli Cipriano dos Santos, Edison Roberto Cabral da Silva. Power Block Geometry Applied to the Building of Power Electronics Converters. IEEE Trans. Educ. 2013; 56(2): 191-198.

[21] A Abramovitz. Teaching behavioral modeling and simulation techniques for power electronics courses. IEEE Trans. Educ. 2011; 54(4): 523-530. 
[22] S Finco, W Melo, F Castaldo, J Pomilio, B Borges, P Santos. A smart power integrated circuit educational tool. IEEE Trans. Power Electron. 2007; 22(4): 1290-1302.

[23] C Mi, Z Shen, T Ceccarelli. Continuing education in power electronics. IEEE Trans. Educ. 2005; 48(1): 183-190.

[24] M Prince, R Felder. The many faces of inductive teaching and learning. J. College Sci. Teaching. 2007; 36: 14-20.

[25] DW Cooper, et al. Cooperative learning: Increasing college faculty instructional productivity. ASHEERIC Higher Education Rep. 1991; 4. 